\title{
The European Union and Global Multilateral Governance - an interdisciplinary research project: Research Notes (Part 2)
}

\section{Jan Wouters, Hans Bruyninckx, Stephan Keukeleire, Tim Corthaut, Sudeshna Basu \& Simon Schunz}

Project:

Dates:

Project Leaders:

Project Researchers:

Funding:
Collaborative Interdisciplinary Research Project

15 November 2006 - 14 November 2010

Jan Wouters (Director of the Leuven Centre for Global Governance Studies, Professor of International Law and International Organisations, University of Leuven)

Hans Bruyninckx (Professor of International Relations and Global Environmental Governance, University of Leuven)

Stephan Keukeleire (Jean Monnet Professor of European Politics, University of Leuven, College of Europe)

Tim Corthaut (Assistant, Institute of European Law, University of Leuven)

Sudeshna Basu (PhD Candidate, Faculty of Law, University of Leuven) Simon Schunz (PhD Candidate, Faculty of Social Sciences, University of Leuven)

Research Fund of the University of Leuven

In a previous edition of the Journal of Contemporary European Research, we introduced the interdisciplinary research project "The EU and Global Multilateral Governance" (see Vol. 4, No. 1, March 2008). In the meantime, the project is well under way. This second research note provides the opportunity to discuss first results of an initial mapping of the field of study and of subsequent efforts to come to a common conceptual framework for studying the EU's role in multilateral fora. The contribution closes with a brief consideration of outstanding challenges and of the research that is currently being conducted.

\section{The EU in global multilateral governance - a multifaceted field of study}

In the first phase of the project, the intention was to obtain a detailed overview of the field of study. Based on an analysis of primary sources (EU, UN and other bodies' legal and political documents etc.), legal analysis and a review of both legal and political science literatures, the EU's participation in a number of global governance arrangements across a range of topics was mapped. The multilateral fora that were 
studied included bodies such as the United Nations (UN) General Assembly, the UN Children's Fund (UNICEF), the International Labour Organization, the UN Environmental Programme and the World Health Organisation.

This inductive exercise yielded many significant insights, but also generated a number of new questions. The most striking outcome was probably the affirmation that even in view of this very complex and multifaceted field of study, the topic has and continues to be analysed within each respective discipline without any interdisciplinary exchanges. It confirmed earlier assumptions that the most suitable way of getting to the bottom of the topic was to conduct in-depth single and comparative case studies.

In terms of concrete empirical results, several other observations were made. Firstly, the analysis demonstrated that the EU is active across a wide spectrum of global governance fora, but that this activity can vary a lot. Variation concerned not only the extent, but also the form that the Union's participation in various multilateral arenas takes. Aside the fact that the European Community has been granted different legal statuses in different multilateral institution ${ }^{1}$, it is also often represented differently (by the Commission or by the Council Presidency) and decides and coordinates differently internally from one forum to the next. Secondly, the EU's role and impact in the various global governance fora seemed to vary a lot. While the Union appears as a leading actor in the UN climate regime, for instance, it seems to not receive the same recognition in fora such as the Human Rights Council. This and other examples demonstrated a need for greater attention to understanding and explaining the EU's activities and influence. Questions were concretely posed with regard to explaining this variance. No pattern could be detected that would suggest a significant correlation between the Union's legal status in an institution and its impact on the functioning of this body. Rather, the EU's informal activities seemed quite important in determining its performance in specific bodies.

The literature review that complemented the inductive exercise allowed us to gain a comprehensive overview of the available research in the affected disciplines, i.e. EU and International Law, EU (foreign policy) and global governance studies. Each of these disciplines clearly restricts its considerations to specific aspects of the EU's participation in global multilateral governance. International lawyers tend to focus on the conditions and outcome of granting the EU - a regional integration organisation - access to global fora. Scholars of EU Law focus on the Union's competences in its external activities, notably with respect to international treaty-making. On the political science side, EU foreign policy experts have concentrated on examining the EU's actorness, i.e. its capacity to act at the global level, in an attempt at determining its international role. Finally, in studies of global governance, which are preoccupied with the formal and informal institutional architectures of governance arrangements, the EU plays so far virtually no role.

Both the empirical findings and the overview of existing research yielded thus a great number of open questions, strongly confirming the necessity for more systematic research on this topic. With their apparent complementarities, both also laid the

\footnotetext{
${ }^{1}$ From a legal perspective, it is the European Community (EC) that possesses international legal personality and is granted formal access to multilateral institutions, not the European Union. This however does not preclude the fact that the Union in the future may, regardless of the Treaty of Lisbon coming into force, accede to international organisations. It has become custom though to refer to the EU in studies of the EC's and the EU's external activities. Three different membership statuses have been granted to the Community in multilateral institutions. Full membership, which entitles access to all meetings and the rights to vote and intervene, has been granted to the EC, most prominently, in the WTO and FAO. A full participant status, which allows the Community to participate without any voting rights having been granted, e.g. at the 2002 World Summit on Sustainable Development (WSSD). Finally, in most institutions, the EC has the status of observer. This entails no right of vote and the right to intervene only after all full members have done so.
} 
foundations for the subsequent step of designing an approach towards systematically studying the Union's participation in governance fora.

\section{Studying the EU in multilateral governance - towards an interdisciplinary approach}

The design of an interdisciplinary framework parted from the assumption that any attempt at bridging the gap between political and legal science needed to "critically reconsider (...) the foundational concepts on which these bridges" can be constructed (Reus-Smit 2004: 2). First analytical units and concepts had emerged from the inductive exercise and literature review. They were employed to develop a tool for studying the EU's participation in global multilateral governance that reflects the perspectives of all four disciplines (Basu/Schunz 2008).

The gap between legal and political science approaches was first overcome at the regional level of analysis. Analytical categories that have enjoyed importance in EU law and EU foreign policy studies were combined into four concepts: (1) representation, which includes an analysis of the EU's legal competences and of the de facto, informal arrangements on who negotiates for the EU in a given forum; (2) internal coordination, which calls for an assessment of the decision-making procedures followed within the Union and of the interaction between Member States and the EU institutions prior to and during international negotiations, (3) legal, diplomatic and economic foreign policy instruments, which necessitates an analysis of the available and actually employed tools of EU foreign policy activity; and (4) objectives, which requires assessing the Treaty as well as political and strategic objectives the EU may have for and when becoming active in a given issue area. Taken together, these categories allow for determining the EU's impetus behind participating and its actual performance in multilateral fora.

But the exercise did not stop here. The gap between the two disciplines was also overcome at the international level of analysis. Two categories were discovered as being of prime importance: recognition and processes. Recognition embodies both de jure (eg. EU legal status) and de facto (who is representing the EU) dimensions which are considered as preconditions for the $\mathrm{EU}$ to be active in a multilateral governance forum. Processes also consist of both legal and political science aspects as, firstly, EU behaviour is enabled and restrained by the rules of procedures of a multilateral institution, and, secondly, in the political science context informal processes of interaction have the capability to rise above legal restrictions and are crucially important for understanding the Union's performance in a governance forum.

Bringing all of these concepts together in one framework helps to overcome inter- and intra-disciplinary borders and proves to be a useful descriptive-analytical tool for approaching this intricate subject matter in its entirety. Further, applying the framework allows for systematic comparison of EU activities across various bodies. Finally, this descriptive tool can be employed flexibly either as the basis for more theoretically enhanced studies with an explanatory aspiration or, e.g. in legal studies, as a basis for gaining greater insights into the "living law" dimensions.

\section{Challenges}

In the course of the first phases of the research project many challenges emerged. First, achieving a common conceptual language entails many trial and error processes primarily based on the fact that both political and legal science have their own individual research interests and corresponding analytical units and methodology. Our endeavour to find a common language necessitated intensive dialogue. Through such dialogue it was realised that common research interests often do exist, but are expressed with different concepts. Following finding parallels between commonly used concepts in each discipline we were faced with the additional challenge of 
prioritising areas of importance. For example, in legal studies an emphasis is placed on the EU's legal status in multilateral organisations, a key facet which sets the foundation of how and to what extent the EU can contribute to the functions of an organisation. Conversely, EU foreign policy studies go directly one step ahead to assessing the EU's performance by examining for example EU representation, without much legal consideration. However, at this very point of departure, it was recognized that each priority area in each discipline serves to be mutually benefiting and undeniably dependent upon one another. This led to a third challenge which was finding a way to take a balanced approach to examining the issues at hand. A major challenge in conducting interdisciplinary research is ensuring that each discipline is represented in a balanced manner and that the output of the research will be presented accordingly. Furthermore a methodological balance is required. One suitable way of combining political science with legal research methodologies is process-tracing, a method which strives "to account for outcomes by identifying and exploring the mechanisms that generate them" (Bates et al. 1998: 12). Finally, while most have been accepting and positive about interdisciplinary research as such we have on occasion been faced with scepticism notably in respects to the extent a discipline, independently, can truly utilise and benefit from such a framework without, for example, "taking the law out of international law" (Byers 1997: 201).

\section{Conclusion}

Having established an interdisciplinary framework which demonstrates a common understanding of approaching our subject of study, the next phase of the project looks more specifically into the European Union's participation in selected multilateral governance arrangements: UN Framework Convention on Climate Change, the International Criminal Court, the Human Rights Council and the Third Committee of the UN General Assembly. The insights gained from the inductive exercise will be applied in the course of the case analyses in order to achieve a comprehensive overview of how the EU fares in these institutions. In its concluding phase, the project will compare and contrast the findings of the case studies and will outline general conclusions that will help facilitate to develop a wider research agenda and valuable policy recommendations for the EU. The final results of the project will be summarized in a future volume of the Journal of Contemporary European Research.

\section{References}

Basu, S. and Schunz, S. (2008). Pathways for an interdisciplinary analysis: legal and political dimensions of the European Union's position in global multilateral governance, Leuven: Centre for Global Governance Studies.

Bates, R.; Avner, G.; Levi, M.; Rosenthal, G.L. and Weingast, B (1998). Analytic Narratives. Princeton, NJ: Princeton University Press.

Byers, M. (1997). 'Response: Taking the Law out of International Law: A Critique of the Iterative Perspective', Harvard International Law Journal, 38 (1), pp. 201-205.

Reus-Smit, C. (ed.) (2004). The Politics of International Law. New York: Cambridge University Press.

Wouters, J.; Basu, S. and Schunz, S. (2008). Meeting the challenges of a multilateralized world? The 'multilaterability' of the European Union. Leuven: Centre for Global Governance Studies.

Wouters, J.; Bruyninckx, H.; Keukeleire, S.; Corthaut, T.; Basu, S. and Schunz, S. (2008). 'The European Union and Global Multilateral Governance - an interdisciplinary research project: Research Notes (Part 1)', Journal of Contemporary European Research 4 (1), pp. 52-55. 